\title{
Synthesis and Characterization of Photoswitchable Fluorescent Silica Nanoparticles
}

\author{
Jonas Fölling, Svetlana Polyakova, Vladimir Belov, Alfons van Blaaderen, \\ Mariano L. Bossi, * and Stefan W. Hell
}

$\boldsymbol{W}_{e}$ have designed and synthesized a new functional (amino reactive) highly efficient fluorescent molecular switch (FMS) with a photochromic diarylethene and a rhodamine fluorescent dye. The reactive group in this FMS -N-hydroxysuccinimide ester-allows selective labeling of amino containing molecules or other materials. In ethanolic solutions, the compound displays a large fluorescent quantum yield of $52 \%$ and a large fluorescence modulation ratio $(94 \%)$ between two states that may be interconverted with red and near-UV light. Silica nanoparticles incorporating the new FMS were prepared and characterized, and their spectroscopic and switching properties were also studied. The dye retained its properties after the incorporation into the silica, thereby allowing lightinduced reversible high modulation of the fluorescence signal of a single particle for up to 60 cycles, before undergoing irreversible photobleaching. Some applications of these particles in fluorescence microscopy are also demonstrated. In particular, subdiffraction images of nanoparticles were obtained, in the focal plane of a confocal microscope.

\author{
Keywords: \\ - colloids \\ - fluorescence microscopy \\ - molecular switches \\ - photochromism \\ - silica nanoparticles
}

\section{Introduction}

Photochromism, that is, the change of the optical-absorption spectrum by light irradiation, is a key feature for the construction of all-optical molecular and supramolecular functional devices. ${ }^{[1]}$ Likewise, fluorescence emission constitutes a highly sensitive readout signal, with a large signal-tonoise ratio and excellent spatial resolution. Consequently, the combination of these two properties opens up interest-

[*] J. Fölling, S. Polyakova, Dr. V. Belov, Dr. M. L. Bossi, Prof. S. W. Hell

Department of NanoBiophotonics

Max Planck Institute for Biophysical Chemistry

Am Fassberg 11, 37077 Göttingen (Germany)

Fax: $(+49)$ 551-2012506

E-mail: mbossi@gwdg.de

Prof. A. van Blaaderen

Soft Condensed Matter Group

Debye Institute, Utrecht University

Princetonplein 5, 3584 CC Utrecht (The Netherlands) ing applications in areas such as optical data storage ${ }^{[2]}$ and biological imaging. ${ }^{[3]}$ However, the use of photochromic fluorescent compounds in biology and other fields may be limited by their low solubility in aqueous media, cytotoxicity, $\mathrm{pH}$ dependence of the fluorescence, and so on. A promising solution to most of these problems ${ }^{[4-6]}$ is to encapsulate the fluorophore inside a nanoparticle (NP). The additional advantages of this strategy are stronger signals, ${ }^{[4]}$ facile incorporation of multiple tags for multiplexed encoding, ${ }^{[7,8]}$ and the possibility to bestow the NP surface with diverse molecular functionalities. ${ }^{[7,9]}$ Despite the huge potential of photoswitchable fluorescent NPs, only a few examples have been reported to date: ${ }^{[10-15]}$ polymer NPs, ${ }^{[14,15]}$ surfactantfree organic NPs, ${ }^{[10,12]}$ and quantum dots (QDs). ${ }^{[11,13]}$ While QDs provide a photostable emission and wide absorption bands, their use is hampered by blinking, cytotoxicity, and incompatibility with aqueous media, unless these issues are counteracted by an adequate surface modification. ${ }^{[16]}$ Polymer NPs also present some drawbacks in aqueous media, 
such as agglomeration or $\mathrm{pH}$-dependent swelling. ${ }^{[8,17]}$ The emission properties of organic nanoparticles ${ }^{[10,12]}$ and QDs are size dependent. In contrast, the encapsulation of the probe in silica NPs constitutes a versatile alternative considering that silica is hydrophilic, fully biocompatible, and easily doped with fluorescent probes. ${ }^{[18]}$ Moreover, silica NPs are readily prepared in many monodisperse sizes. ${ }^{[19]}$

Here we report on the construction of fluorescent sizetunable silica NPs whose fluorescence emission can be repeatedly modulated. This modulation is based on a novel molecular switch (Scheme 1) incorporated (covalently

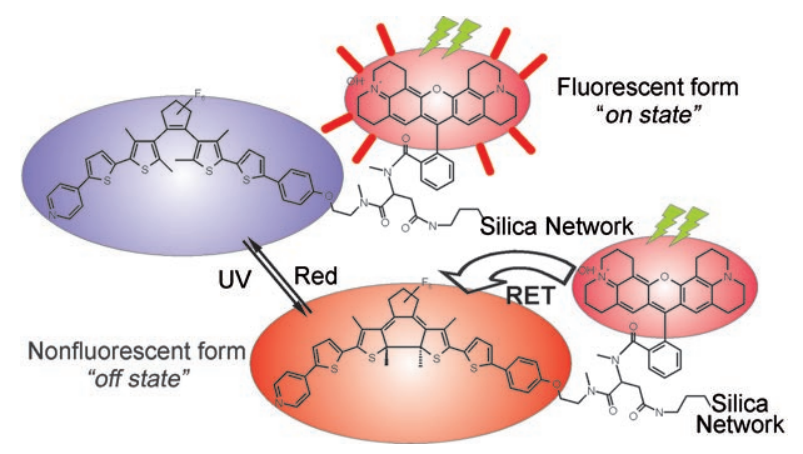

Scheme 1. Chemical structure of the fluorescent molecular switch Rh$A A-D A E$ and the photochromic reaction responsible for the fluorescence modulation. The fluorophore moiety is excited with green light: red light is emitted in the on state, while resonant energy transfer prevents this emission in the off state.

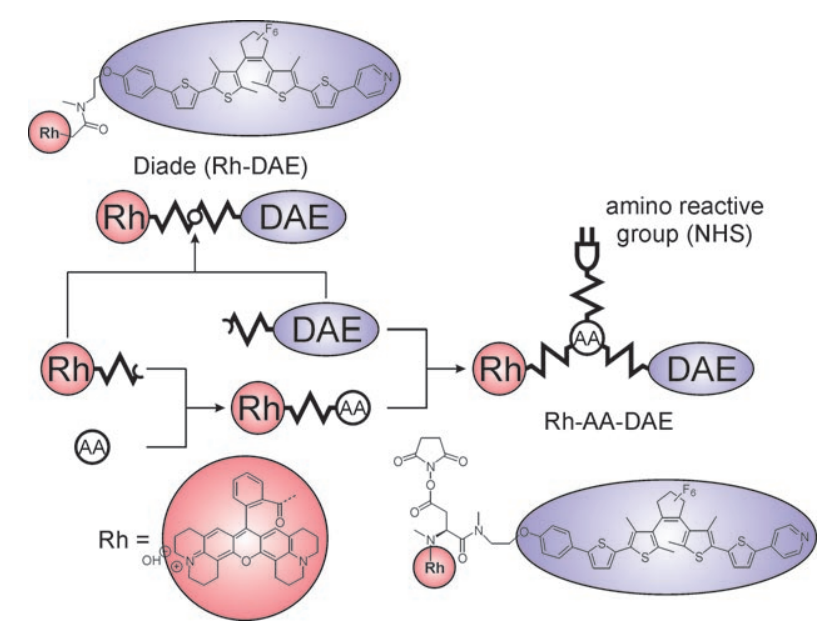

Scheme 2. Schematic representation of the strategy used to obtain a functionalized (amino reactive) fluorescent molecular switch (Rh-AA$D E A)$, based on building blocks previously used to prepare non functionalized diades (Rh-DAE).

erties of the building blocks so that only one of the isomers of the DAE is highly efficient as an energy acceptor. In the present work we prepared a modified fluorescent switch, named Rh-AA-DAE, based on the previously described FMSs. The strategy, shown in Scheme 2, consisted of the insertion of a further functionality (an amino reactive NHS ester) between the photochromic unit (compound 6, Scheme 3) and the rhodamine 101 fragment, in order to tag these compounds to other molecules (e.g., a monomer) or linked) into the silica network. The emission properties of the particles depend neither on their size (within a useful range) nor on whether the marker is in the particle core or in a shell. We also report the synthesis of this molecular switch, as well as its properties in solution and when incorporated in silica particles of different sizes, both into the core or in the shell.

Recently, we reported fluorescent molecular switches (FMS) with improved performance for super-resolution microscopy. ${ }^{[18,20]}$ The diades (Scheme 2) consisted of rhodamine-101 (Rh) linked to a photochromic (PC) diheteroarylethene (DAE) as a bistable resonance-energytransfer (RET) acceptor. A high switching contrast was achieved by tuning the absorption and emission prop-
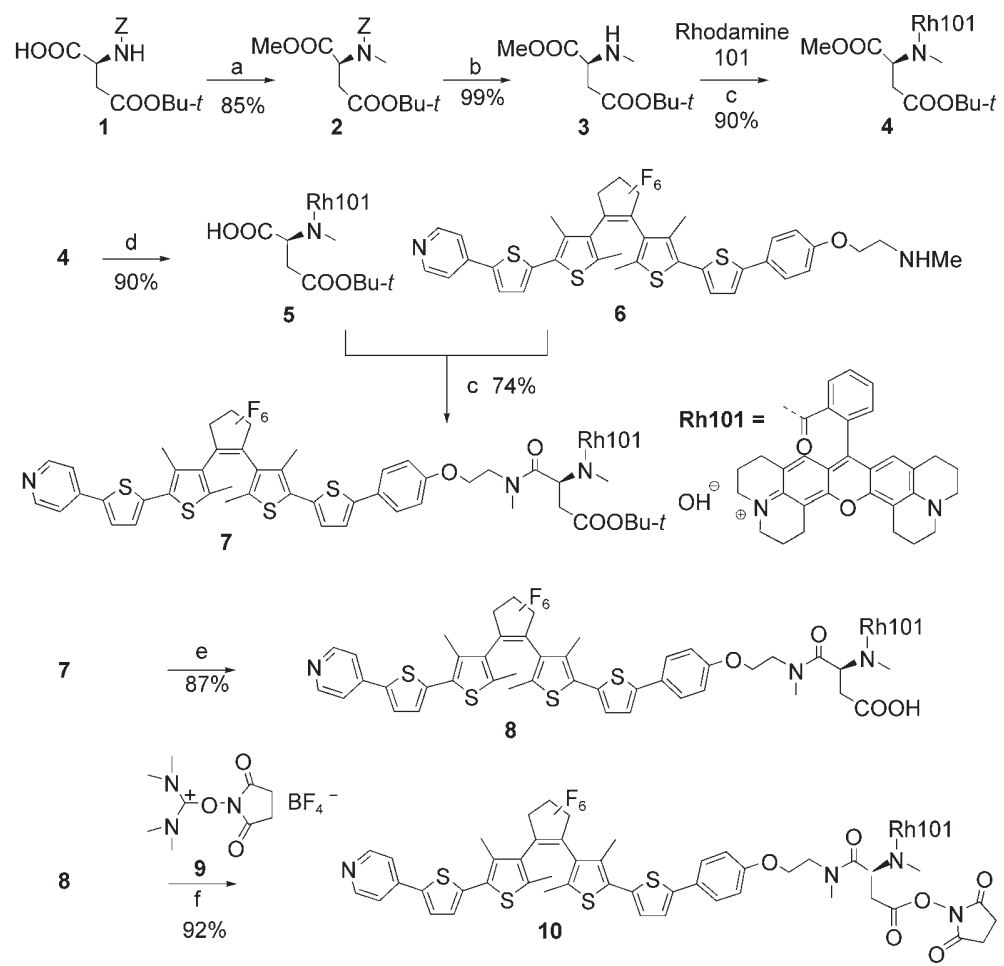

Scheme 3. Reagents and conditions: a) Mel, $\mathrm{Ag}_{2} \mathrm{O}$, DMF, room temperature (RT), $16 \mathrm{~h}$; b) $\mathrm{H}_{2}$ (1 atm), $10 \% \mathrm{Pd} / \mathrm{C}$ (MERCK, oxidized form), EtOAc, RT; c) HATU, Et $\mathrm{N}_{2} \mathrm{CH}_{2} \mathrm{Cl}_{2}, \mathrm{RT}$; d) $1 \mathrm{M}$ aq. $\mathrm{NaOH}, \mathrm{MeOH}, \mathrm{THF}$, 3 h, RT; e) TFA, $\mathrm{Et}_{3} \mathrm{SiH}, \mathrm{CH}_{2} \mathrm{Cl}_{2}, 0^{\circ} \mathrm{C}-\mathrm{RT}$; f) $i \mathrm{Pr}_{2} \mathrm{NEt}, \mathrm{DMF}, 2 \mathrm{~h}, \mathrm{RT}$. 
incorporate them into a material to which the switching properties are to be conferred. We extended the bridge between the two parts of the diades ${ }^{[20]}$ by inserting an aspartic acid (AA) that acts as a branching point and possesses an additional carboxylic group that may be easily transformed into the corresponding NHS ester, a useful amino-reactive functional group. This new functionality did not alter the individual properties of the fluorescent and photochromic building blocks. The additional amino acid only adds three bonds to the linker, representing a small increase in the total length of the whole bridge as compared with the calculated Förster radius (ca. $50 \AA$ ). It is therefore expected that the efficiency of the resonant energy transfer $\left(E_{\mathrm{RET}}\right)$ between the donor and the acceptor in the final compound will not be significantly reduced.

The functionalized FMS was coupled to (3-aminopropyl)triethoxysilane and then incorporated in the synthesis of the particles by hydrolysis and condensation with tetraethyl orthosilicate in mixtures of water, ammonia, and ethanol. In this way, the probe is chemically bonded to the silica network. ${ }^{[18]}$ This avoids any leaking into the solvent or into standard microscopy immersion media, which is an undesired effect usually observed with stained polymer beads when the fluorophores are incorporated by swelling or not bound to the polymer backbone.

\section{Results and Discussion}

In the previously described diades DAE-Rh (see the chemical structure in Scheme 2), ${ }^{[20]}$ an amide bond was used to link the two building groups. Therefore, it was natural to insert an amino acid as a branching point in the newly designed functional FMS. Aspartic acid was selected because it has an additional carboxylic group that can be further functionalized. This amino acid has a total of three functional groups, which should be initially orthogonally protected. Therefore, we started from the commercially available tertbutyl ester 1, and in one step transformed it into 1-methyl 3tert-butyl $N$-methyl- $N$ - $Z$-aspartate 2 (Scheme 3).

An additional $\mathrm{N}$-alkyl group is essential for blocking the (reversible) cyclization, which involves the $\mathrm{NH}$ residue of the amide and the internal tetrasubstituted $\mathrm{C}=\mathrm{C}$ bond of the aromatic rhodamine system. This kind of cyclization, well known in the series of rhodamine secondary amides, converts highly colored fluorescent species into colorless products with nonaromatic central rings and a five-membered spiro cycle with the tertiary amide bond. ${ }^{[21]}$ Diester 2 pos- sesses the required orthogonal protection of three functional groups. The $N$-methyl amino group was then deblocked, acylated with rhodamine 101 in the presence of a base and the strongly activating coupling agent (HATU), and the diester 4 was saponificated with aqueous $\mathrm{NaOH}$. The photochromic unit $\mathbf{6}^{[20]}$ and the mono acid 5 were connected with each other; the tert-butyl ester group was removed, and the $\omega$-carboxy group was activated in the reaction with $N$-hydroxysuccinimidyl carbonate and a base. The final active ester 10 (functionalized FMS) was found to lose its activity on silica gel and also during its isolation by the reversedphase high-performance liquid chromatography (HPLC). Therefore it was characterized by NMR and MS spectra, and was used in further reactions without purification (after evaporation of dimethylformamide (DMF) from the reaction mixture).

The properties of compound $\mathbf{7}$ in ethanolic solutions were measured to evaluate the effect of the amino acid inserted between the building blocks DAE and Rh (Table 1). We have previously shown ${ }^{[20]}$ that the absorption and emission spectra of the diades Rh-DAE is the superposition of the spectra of each building block. Therefore, it was not surprising that the addition of AA did not have any effect on the spectral properties. The efficiency of energy transfer between Rh and both isomers of DAE was expected to be altered due to the different linker used (that is, due to the difference in the distance between the RET donor and acceptor). However, only the RET efficiency for the open isomer (on state) was significantly altered, which resulted in a slightly improved fluorescence modulation. All relevant measured parameters for compounds Rh-DAE and compound 7 (a model for Rh-AA-DAE) are listed in Table 1.

The spectroscopic and switching properties of 30-nmsized particles containing Rh-AA-DAE in ethanolic suspension are shown in Figure 1. Compared to the dye dissolved in ethanol, both the absorption and emission spectra are not substantially altered, except for a red shift of $5 \mathrm{~nm}$ in each spectrum. Figure $1 \mathrm{~A}$ and $\mathrm{B}$ display the changes of the absorption and fluorescence signal of the particles induced by irradiation with UV $(375 \mathrm{~nm})$ and red $(671 \mathrm{~nm})$ light. About $94 \%$ of the total signal was reversibly modulated. Irradiation with UV light switched the DAE moiety to the offstate isomer. This was evidenced by the appearance of its absorption band at $640 \mathrm{~nm}$ and the concomitant decrease in fluorescence emission. The on state was regenerated by irradiating this band with red light. The inset in Figure 1B shows the dynamics of this switching, as evidenced by illumination of the compound with green light $\left(\lambda_{\mathrm{ex}}=543 \mathrm{~nm}\right)$,

Table 1. Absorption and emission maximum of the fluorophore $\left({ }^{\mathrm{Rh}} \lambda_{\mathrm{MAX}}\right)$; fluorescent quantum yields ( $\left.\Phi_{\text {Fluo }}\right)$, conversions in the photostationary state $\left(a_{\mathrm{PS}}\right)$, fluorescence modulations $\left(\mathrm{FM}=100 \times\left[1-I_{\mathrm{F}, \text { off }} / /_{\mathrm{F}, \mathrm{o}}\right]\right)$, and RET efficiencies $\left(E_{\mathrm{RET}}\right)$ of both isomers, for the diade Rh-DAE, ${ }^{[20]}$ the functional Rh-AA-DAE compound 7, and the 30-nm nanoparticles in ethanolic solutions (suspensions).

\begin{tabular}{|c|c|c|c|c|c|c|c|}
\hline \multirow[t]{2}{*}{ Compound } & \multicolumn{2}{|c|}{${ }^{\mathrm{Rh}} \lambda_{\operatorname{MAX}}(\mathrm{nm})$} & \multirow[t]{2}{*}{$\Phi_{\text {Fluo }}$} & \multirow[t]{2}{*}{$a_{\mathrm{PS}}$} & \multirow[t]{2}{*}{ FM } & \multicolumn{2}{|c|}{$E_{\mathrm{RET}}$} \\
\hline & Abs. & Emiss. & & & & on state & off state \\
\hline Rh-DAE & 585 & 603 & 0.29 & $0.98^{[a]}$ & $92 \%$ & 0.72 & 0.98 \\
\hline Rh-AA-DAE & 585 & 604 & 0.52 & $0.98^{[a]}$ & $94 \%$ & 0.46 & 0.98 \\
\hline Nanoparticles & 590 & 610 & 0.52 & $0.59^{[b]}$ & $94 \%$ & - & - \\
\hline
\end{tabular}

[a] From HPLC measurements; [b] From absorption measurements (assuming absorption coefficients are the same in silica and in solution). 

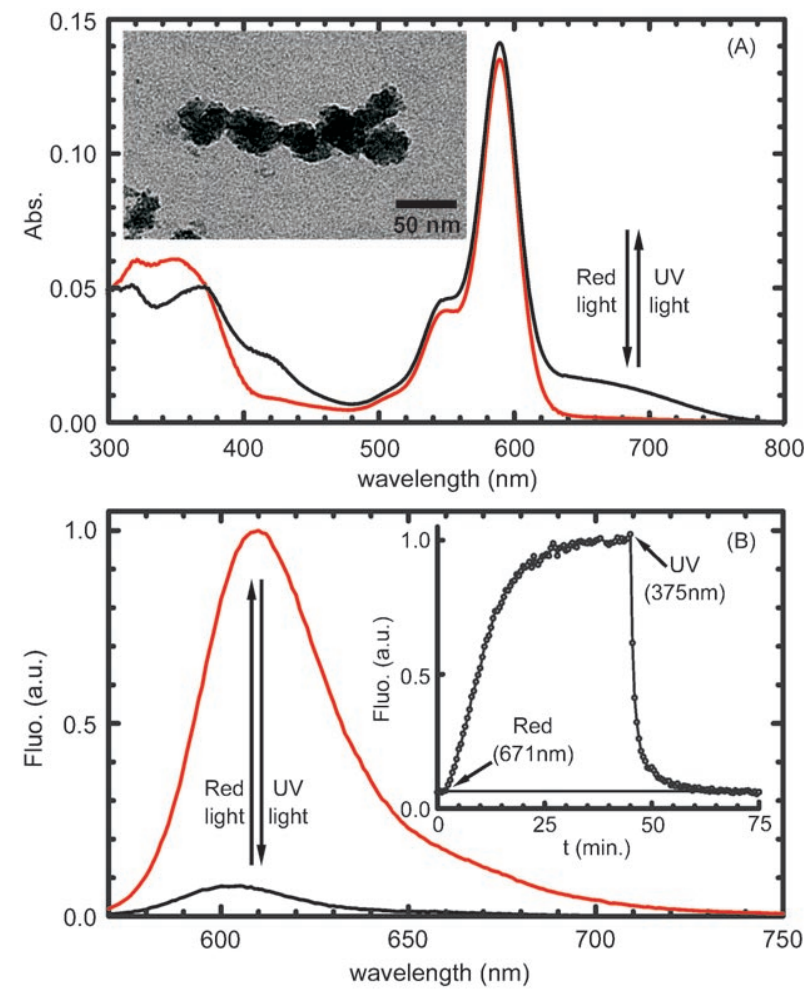

Figure 1. Absorption (A) and emission (B) spectra of 30-nm nanoparticles with Rh-AA-DAE incorporated, irradiated with UV (black line) and red light (red line), in ethanolic suspension. The inset in (B) shows the kinetics of the emission modulation for a complete irradiation cycle with light of $671 \mathrm{~nm}(40 \mathrm{~mW})$ and $375 \mathrm{~nm}(\mu \mathrm{W})$ in a total volume of $3 \mathrm{~mL}$. A TEM image of the nanoparticles is also provided in (A).

which excites the fluorescent moiety. The particles were initially irradiated with UV light, and therefore they were predominantly in the off state. Thus, fluorescence was sequentially switched on and off with $671 \mathrm{~nm}$ and $375 \mathrm{~nm}$ light, respectively.

A conversion of $59 \%$ was estimated from the absorption spectra for the FMS inside the silica, assuming there was no substantial change in the absorption coefficients of the two Rh-AA-DAE isomers, as compared with solution. A lower conversion in constrained media was previously reported for some diheteroarylethenes in polymers. ${ }^{[2,22]}$ However, the fluorescence modulation in the particles was as large as the one observed for the model Rh-AA-DAE compound in solution. This can be explained if the mean distance between the dopants in the particles is small enough to allow an efficient intermolecular energy transfer, that is, the off state of a Rh-AA-DAE molecule can accept the energy from the fluorophore of one or several neighboring molecules as well as from the one in its own molecule. To support this conclusion, we measured the emission as a function of the conversion for the particles and for the free dye in ethanol (Figure 2). The linear dependence expected for a one-toone ratio between the donor and the acceptor was observed for the free dye, while particles presented a clear deviation from this linear behavior. The same $\Phi_{\text {Fluo }}$ was observed for the particles and for the free dye in solution (see Table 1),

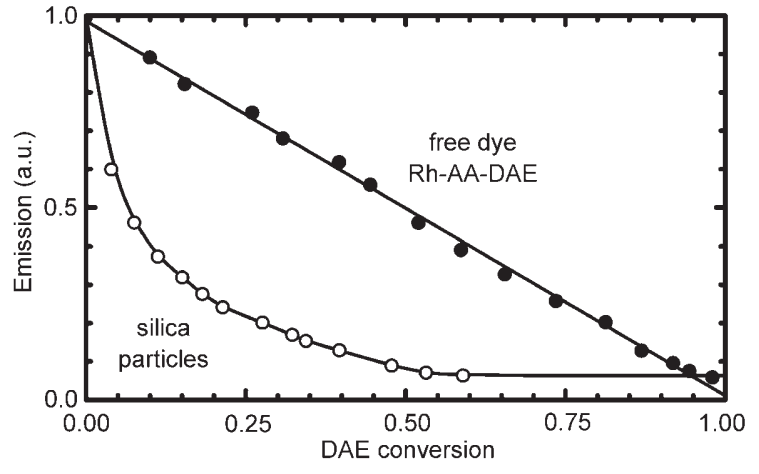

Figure 2. Emission at the maximum wavelength of the fluorophore (Rh) as a function of the conversion of the photochromic moiety (DAE) for the dye Rh-AA-DAE in ethanolic solution (full symbols) and in silica nanoparticles of 30-nm diameter (hollow symbols). The line in the free dye is the best linear fit, while that for the particles is just a guideline for the eye.

indicating that the average distance between dye molecules had to be larger than the Förster radius for homo-RET (rhodamine-rhodamine), but it had to be smaller than that between the rhodamine and the photochromic moiety. These intermolecular interactions are responsible for the high fluorescence modulation obtained in the particles despite of the lower conversion of the photochromic unit.

Larger particles containing the same dye were also prepared with diameters of $120 \mathrm{~nm}, 250 \mathrm{~nm}$ and $600 \mathrm{~nm}$. All of them displayed similar properties as their 30-nm counterparts; in particular they exhibited switching ratios of at least $85 \%$. The differences in the fluorescence modulation can be ascribed to small differences in the concentrations of the dye in the silica resulting from the different conditions during their synthesis.

The switching properties of the 30-nm particles doped with $\mathrm{Rh}$-AA-DAE were also tested in a confocal microscope. Single beads were centered in the focal spot and submitted to successive irradiation cycles with a $375-\mathrm{nm}$ and 671-nm laser. The irradiation times and laser powers measured in the aperture of the objective lens for each laser were $15 \mathrm{~ms}$ and $66 \mathrm{nW}$ for the UV laser, and $10 \mathrm{~ms}$ and $100 \mathrm{nW}$ for the red laser. Between hemicycles, the intensity of the signal emitted by the bead excited with a 543-nm laser was probed with a laser power of $25 \mathrm{nW}$ (readout dwell time of $2 \mathrm{~ms}$ ), and plotted as a function of the cycle number. Figure 3 shows the first 30 complete cycles where no sign of fatigue is observed. Normally, the beads resisted up to 50-60 cycles before approximately $10 \%$ of the modulation ratio (signal in the off state/signal in the on state) was lost. This fatigue was evidenced as an increase in the signal in the off state, with no significant alteration of the signal in the on state, indicating that the photochromic part of the molecule underwent irreversible photodamage. The difference observed in the fluorescence modulation ratio between bulk experiments (Figure 1B) and single-particle experiments (Figure 3) was due to the cross talk observed for the excitation laser at the intensities used in the confocal microscope that also effected the photochromic reaction from the off to the on state. In fact, reducing its intensity resulted in 


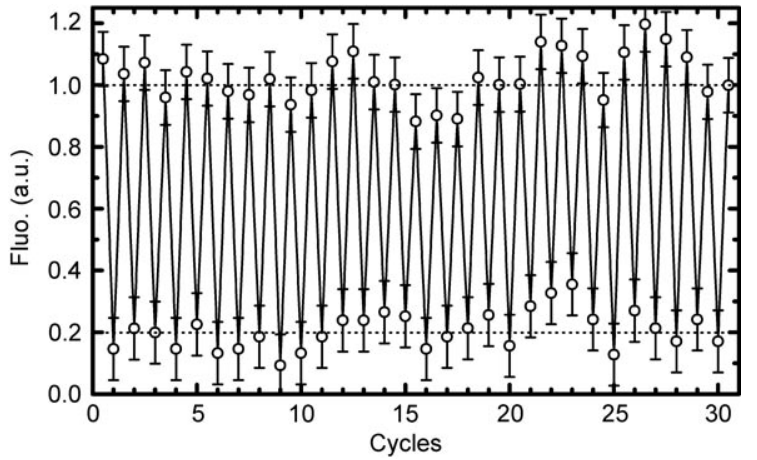

Figure 3. A series of 30 successive complete irradiation cycles (UV/ red light) performed on a single silica particle in a confocal microscope.

a better modulation but noisier data were obtained. The intensity selected in all experiments was then a compromise between these two effects.

A promising application for our fluorescence switching NPs is to trace objects such as organelles or biomolecular agglomerations in a cellular environment. Switching fluorescence signals on and off is very useful in this regard since it visualizes the temporal evolution of the position of the object to be tracked. However, once the NPs are switched off, the lack of fluorescence signal makes them hard to trace. To have a further control of "switched-off" NPs, and to exemplify their potentiality as fluorescent probes carrying an additional signal, we have functionalized the core of 120-nm-diameter particles with a second dye, namely, Atto-647N. The shell of the NPs was functionalized with Rh-AA-DAE as before. A 20-nm-thick layer of pure silica separating the shell from the core was used to prevent RET between the two dyes.

The double-stained beads were also observed in the confocal microscope with two-channel detection. RhAA-DAE fluorescence was modulated under the same conditions used for the singlestained beads. Figure 4 shows images of these particles adcle (F). sorbed onto a microscopy slide. The fluorescence in the $\mathrm{Rh}$ detection channel (green) was switched on and off with red and UV light respectively (upper images), while the signal in the Atto-647N channel (red) remained unaltered. A contrast of 5:1 was typically obtained in the first channel but it was also dependent on the irradiation times and intensities of the lasers. Since the particles are smaller than the focal spot of the microscope, their size in the images is mainly determined by the latter, and thus by the wavelengths involved. For this reason the size of the particles appears slightly smaller in the $\mathrm{Rh}$ channel. The reversible switching of the particles can be performed at arbitrary locations in the field of view. While only the on-state NPs can be traced in the $\mathrm{Rh}$ channel, all of them can be observed in the other one. The reversibility enables switching the NPs on different locations.

Reversible fluorescent switchable dyes are of great interest to reversible saturable optical fluorescence transitions (RESOLFT) microscopies. ${ }^{[23,24]}$ Based on any molecular transition between a fluorescent and a dark state ${ }^{[25-27]}$ that
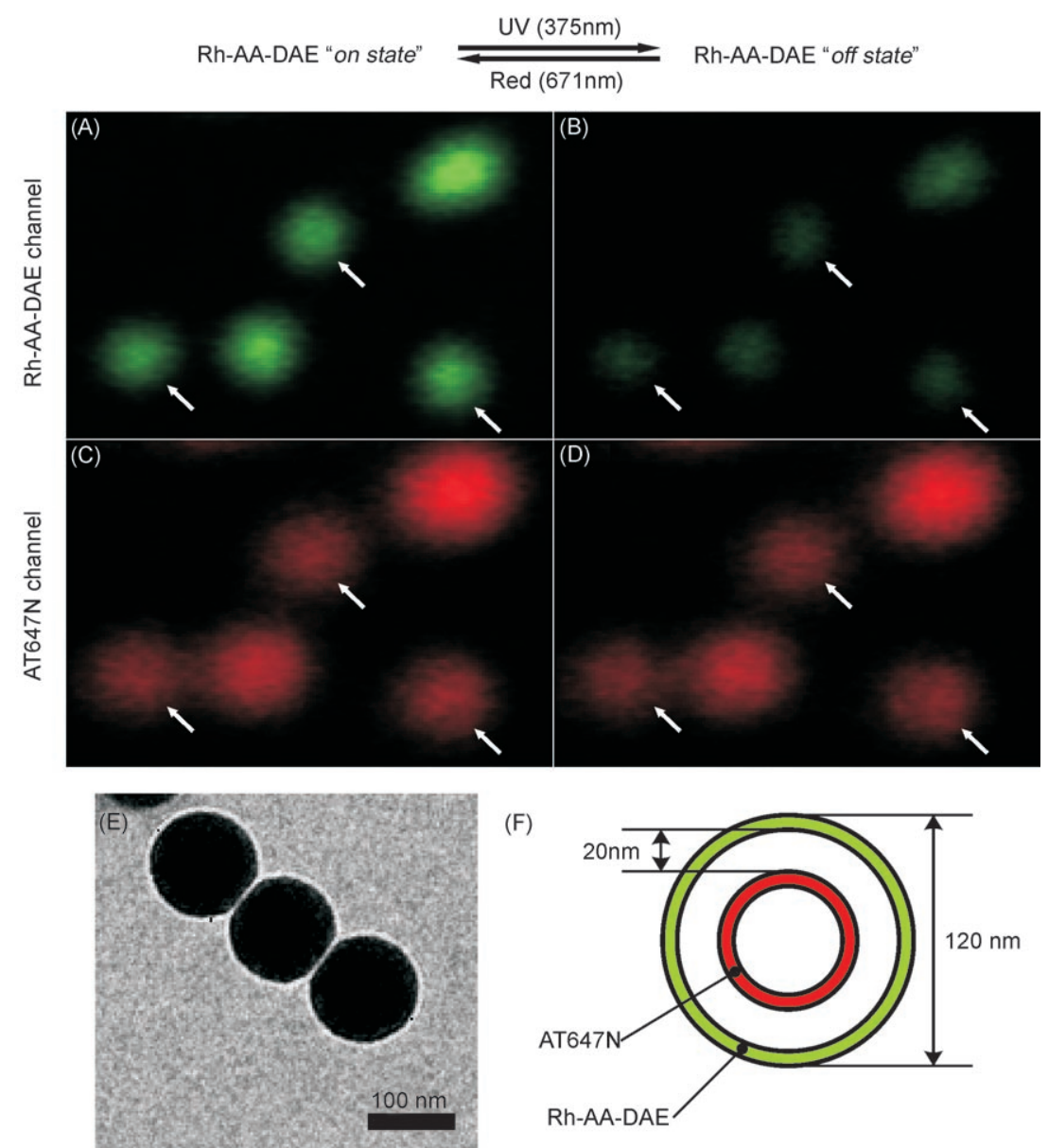

Figure 4. Confocal images of fluorescent NPs $(120 \mathrm{~nm})$ doubly stained with Rh-AA-DAE and AT647N, recorded in two channels. The upper images $(A, B)$ correspond to the rhodamine channel, while the lower ones (C,D) to the ATTO647N channel. The images on the left side $(A, C)$ were recorded in the on state of the PC system (after irradiation with red light), and the ones on the right side (B, D) were recorded in the off state (after irradiation with UV light). The arrows indicate single beads. The lower panel shows a TEM image of the particles (E) and a scheme with the distribution of the dyes inside each parti- 
can be saturated, this family of far-field microscopies has achieved a spatial resolution far below the diffraction limit. ${ }^{[28,29]}$ Organic photochromic dyes are of particular interest because the diffraction barrier can be surpassed using very low intensities of light. Besides the already mentioned advantages arising from the encapsulation of the fluorescent probes (e.g., signal amplification, etc.), nanometer-scale NPs are suitable objects to test the performance of a microscope, such as the spatial resolving power and the measurement of its effective point-spread function ( $\left.\mathrm{PSF}_{\text {eff }}\right)$. To this end, 30$\mathrm{nm}$-diameter nanoparticles doped with Rh-AA-DAE were imaged in the same home-built confocal microscope used in the other experiments, equipped with RESOLFT capabilities by inserting a spatial light modulator (SLM) that allowed PSF engineering of the laser driving the photochromic reaction to the off state for resolution enhancement in one direction. The SLM can be switched on and off so that confocal and enhanced images can be recorded simultaneously. Figure 5 shows line scans in the enhanced direction

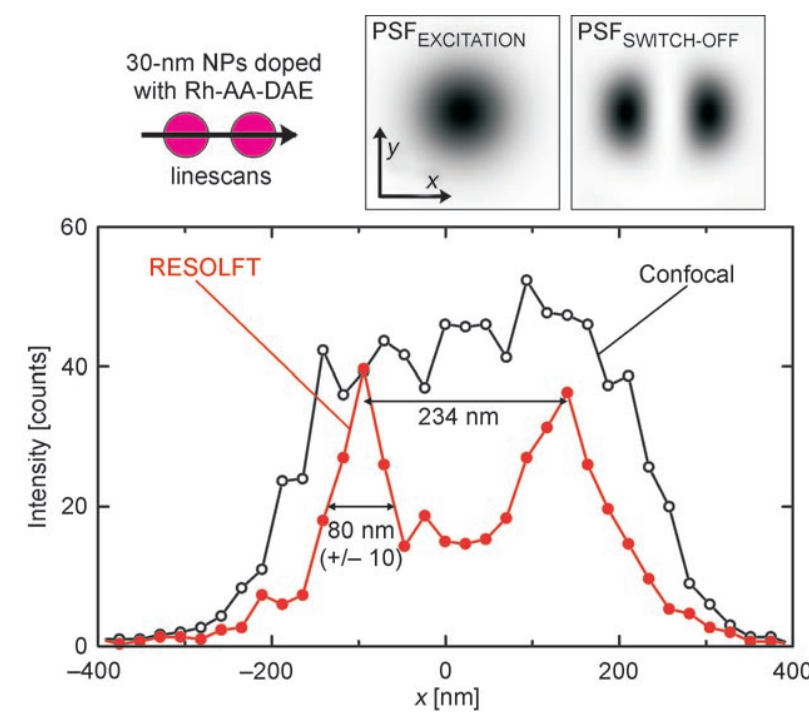

Figure 5. RESOLFT microscopy of switchable nanoparticles. Line scans along the $x$ direction over two neighboring particles measured with a microscope in a conventional confocal mode (black line), and with the enhanced capabilities (red line, RESOLFT). The pixel size used is $10 \mathrm{~nm}$ and the illumination conditions are similar to that used in Figure 4. The excitation PSF $(543 \mathrm{~nm})$ used in both measurements and the switch-off PSF $(375 \mathrm{~nm})$ used in the RESOLFT mode are also shown.

over two close particles separated by $234 \mathrm{~nm}$. While unresolved in the conventional confocal mode, the two particles were clearly resolved in the RESOLFT mode. The low pixelation of these images was intentionally used to avoid exposing the particles to an excessive number of switching cycles. Decreasing the pixel size resulted in irreversible photodamage of the photochromic compound and the consequent loss of contrast. The same effect could be observed in the RESOLFT image when an increased number of measurements was performed to smooth the signal by averaging several line scans. When several scans were performed, similar to the one displayed in each image in Figure 5, a clear differ- ence was observed between the first and the last one in the RESOLFT mode. The newly designed FMS and the prepared silica NPs may find promising applications in this area once the number of cycles a probe or a nanoparticle can tolerate is improved. In this regard, further modifications of the photochromic moiety are necessary to increase its photochemical stability.

\section{Conclusions}

We have successfully prepared a fluorescent photochromic compound, functionalized with an amino reactive group (NHS ester) that can, in principle, be linked to any aminocontaining monomer and then incorporated into different organic or inorganic materials, as we have demonstrated here for silica. The addition of a branching point with the new functionality to the molecule did not affect its spectral and switching properties. The potential utility of this compound is not only limited to the example given here. It can also be used for tagging other molecules or biomolecules of interest, in the same way as other fluorophores that are commonly used. Once incorporated into silica NPs, it retains its fluorescent and switching properties. The NP fluorescence can be repeatedly modulated with UV and visible light. Unlike organic NPs ${ }^{[7 b]}$ or QDs, ${ }^{[16]}$ the emission properties of the silica NPs described in this article are virtually size independent. The particles are suitable for imaging and switching in optical microscopy, thus opening up a large range of applications. The biocompatibility of silica makes them promising for in vivo imaging applications, for example, by applying standard protocols for biomolecular coupling (DNA, ${ }^{[4]}$ antibodies ${ }^{[5]}$ ). The possibility to downscale the silica $\mathrm{NPs}^{[30]}$ to $\approx 10-15 \mathrm{~nm}$ renders them an attractive alternative to direct staining with reversibly photoswitchable fluorescent probes. ${ }^{[3]}$ Some of the advantages of tagging biomolecules with doped nanoparticles as compared with direct attachment of Rh-AA-DAE are signal amplification and easier incorporation of multiple functionalities. We also anticipate that this novel class of functional NPs will find important applications in the colloidal sciences where it is likely to contribute to the realization of functional colloidal crystals whose properties can be switched by light as an external trigger.

\section{Experimental Section}

Synthesis of the amino reactive photochromic fluorescent compound: Melting points (uncorrected) were determined in capillaries using an SMP 10 apparatus (Bibby Sterling Ltd., UK). Routine NMR spectra were recorded with Varian MERCURY-300 and Bruker AM 250 spectrometers at $300\left({ }^{1} \mathrm{H}\right)$ and $75.5 \mathrm{MHz}\left({ }^{13} \mathrm{C}\right.$ and APT), as well as at $250\left({ }^{1} \mathrm{H}\right)$ and $62.9 \mathrm{MHz}\left({ }^{13} \mathrm{C}\right.$ and DEPT), respectively. ${ }^{1} \mathrm{H}$ NMR spectra $(600 \mathrm{MHz})$ were also recorded with a Varian INOVA 600 instrument. All spectra are referenced to tetramethylsilane as an internal standard $(\delta=0 \mathrm{ppm})$ using the sig- 
nals of the residual protons of deuterated solvents: 7.26 for $\mathrm{CHCl}_{3}$ and 2.50 for $\left[\mathrm{D}_{5}\right] \mathrm{DMSO}$. Multiplicities of signals are described as follows: $\mathrm{s}=$ singlet, $\mathrm{d}=$ doublet, $\mathrm{m}=$ multiplet. Coupling constants () are given in Hertz. El-MS were recorded with MAT $95(70 \mathrm{eV})$ and ESI-MS with LCQ spectrometers (Fa. Finnigan). Optical rotations $\left([a]_{D}^{20}\right.$ values) were measured with a Perkin-Elmer polarimeter. HPLC-System (Knauer): Smartline pump $1000(2 \times)$, UV detector 2500, column thermostat 4000, mixing chamber, injection valve with a 20 and $100 \mu \mathrm{L}$ loop for the analytical and preparative columns, respectively; 6-port-3channel switching valve; analytical column: Eurospher-100 C18, $5 \mu \mathrm{m}, 250 \times 4 \mathrm{~mm}$; preparative column: Eurosphere-100 C18, $5 \mu \mathrm{m}, 250 \times 8 \mathrm{~mm}$; solvent A: MeCN $+0.1 \% \mathrm{v} / \mathrm{v}$ TFA, solvent B: $\mathrm{H}_{2} \mathrm{O}+0.1 \% \mathrm{v} / \mathrm{v}$ TFA. Injections of the irradiated solutions in $\mathrm{EtOH}$ allowed direct measurements of the ratios of the open and closed forms at the photostationary state (detection at the isobestic point). Analytical TLC was performed on MERCK ready-touse plates with silica gel $60\left(\mathrm{~F}_{254}\right)$ and developed by molybdatophosphoric acid solution ( $5 \%$ in EtOH). Flash chromatography: MERCK silica gel, grade 60, 0.04-0.063 mm; MACHEREY-NAGEL Polygoprep 60-50 C18; fraction collector RETRIVER II (ISCO). THF and diethylether were dried with sodium benzophenone. Organic solutions were dried over $\mathrm{MgSO}_{4}$. All reactions were carried out with magnetic stirring under positive argon pressure using the standard technique with vacuum-inert-gas manifold, unless stated otherwise. Rhodamine 101 was purchased from FLUKA.

1-Methyl 4-tert-butyl N-benzyloxycarbonyl-N-methyl-L-aspartate (N-Z-N-MeAsp(OtBu)OMe) (2): $4.3 \mathrm{~g}$ (19.0 mmol) of $\mathrm{Ag}_{2} \mathrm{O}$ were added to a solution of $\mathrm{N}$-Z-Asp $(\mathrm{OtBu}) \mathrm{OH} 1$ (Fluka, $1.66 \mathrm{~g}$, $5.0 \mathrm{mmol})$ and $\mathrm{Mel}(10.2 \mathrm{~g}, 72.0 \mathrm{mmol})$ in anhydrous DMF $(15 \mathrm{~mL})$, and the black suspension was vigorously stirred at room temperature for $16 \mathrm{~h}$. Dichloromethane was added to the reaction mixture $(100 \mathrm{~mL})$, and it was filtered through Celite. The filter-cake was washed with dichloromethane $(2 \times 50 \mathrm{~mL})$, and the combined organic solutions were washed with saturated aq. $\mathrm{Na}_{2} \mathrm{~S}_{2} \mathrm{O}_{3}(2 \times 50 \mathrm{~mL})$, water $(8 \times 50 \mathrm{~mL})$ and brine $(50 \mathrm{~mL})$. After drying, they were concentrated in vacuo and the oily residue was purified by chromatography on $\mathrm{SiO}_{2}(100 \mathrm{~g})$ with a hexaneEtOAc mixture $\left(1: 1, R_{\mathrm{f}} \approx 0.6\right)$ to yield the title compound as an oil $(1.5 \mathrm{~g}, 85 \%) .{ }^{1} \mathrm{H} \mathrm{NMR}\left(\mathrm{CDCl}_{3}, 250 \mathrm{MHz}\right), \delta=1.42(\mathrm{~s}, 9 \mathrm{H})$, 2.58-2.73 (m, $1 \mathrm{H}, \mathrm{CH}), 2.91 / 2.94$ (s, 3H, NMe), 2.90-3.03 (m, $1 \mathrm{H}, \mathrm{CH}), 3.56 / 3.71(\mathrm{~s}, 3 \mathrm{H}, \mathrm{OMe}), 4.75-4.97(\mathrm{~m}, 1 \mathrm{H}, \mathrm{CH}), 5.12$ $\left(\mathrm{m}, 2 \mathrm{H}, \mathrm{CH}_{2}\right), 7.33 \mathrm{ppm}(\mathrm{m}, 5 \mathrm{H}, \mathrm{CH}) .{ }^{13} \mathrm{C} \mathrm{NMR}\left(\mathrm{CDCl}_{3}, 62.9 \mathrm{MHz}\right)$, $\delta=27.9(3 \times \mathrm{Me}), 32.7 / 33.7(\mathrm{NMe}), 35.8 / 36.4\left(\mathrm{CH}_{2}\right), 52.3 / 52.4$ $(\mathrm{CH}), 57.0(\mathrm{OMe}), 67.4\left(\mathrm{CH}_{2}\right), 81.1 / 81.3(\mathrm{C}), 127.7(\mathrm{CH}), 127.9$ $(2 \times \mathrm{CH}), 128.4(2 \times \mathrm{CH}), 136.2 / 136.4(\mathrm{C}), 155.7 / 156.2(\mathrm{C}=0)$, $169.6(\mathrm{C}=0), 170.7 \mathrm{ppm}(\mathrm{C}=0) .[\mathrm{a}]_{\mathrm{D}}^{20}=-27.0\left(c=1.33, \mathrm{CHCl}_{3}\right)$. $\mathrm{C}_{18} \mathrm{H}_{25} \mathrm{NO}_{6}$ [351], ESI-MS: $m / z$ (rel. int., \%) $=726$ (12), 725 (48) $[2 \mathrm{M}+\mathrm{Na}]^{+}, 388$ (15), 375 (18), $374(100)[\mathrm{M}+\mathrm{Na}]^{+}$.

1-Methyl 4-tert-butyl N-methyl-L-aspartate (N-MeAsp(OtBu)OMe) (3): A solution of N-Z-N-MeAsp(OtBu)OMe 2 (0.64 g, $1.82 \mathrm{mmol})$ in EtOAc $(20 \mathrm{~mL})$ was flushed with argon and then vigorously stirred with $76 \mathrm{mg}$ of $10 \% \mathrm{Pd} / \mathrm{C}$ (MERCK, oxidized form) in an atmosphere of $\mathrm{H}_{2}$ at normal pressure for $16 \mathrm{~h}$. Then the mixture was flushed with argon, filtered through Celite to remove the charcoal with $\mathrm{Pd}$, the filter-cake was washed with EtOAc $(3 \times 10 \mathrm{~mL})$, and the filtrate was evaporated in vacuo to give the title compound as a colorless oil ( $395 \mathrm{mg}, 99 \%$ ), which was used in the next step without further purification. ${ }^{1} \mathrm{H}$ NMR
$\left(\mathrm{CDCl}_{3}, 250 \mathrm{MHz}\right), \delta=1.40(\mathrm{~s}, 9 \mathrm{H}), 2.37(\mathrm{~s}, 3 \mathrm{H}, \mathrm{NMe}), 2.49-$ $2.67\left(\mathrm{~m}, 2 \mathrm{H}, \mathrm{CH}_{2}\right), 3.42-3.48(\mathrm{~m}, 1 \mathrm{H}, \mathrm{CH}), 3.71 \mathrm{ppm}(\mathrm{s}, 3 \mathrm{H}$, OMe). ${ }^{13} \mathrm{C} \mathrm{NMR}\left(\mathrm{CDCl}_{3}, 62.9 \mathrm{MHz}\right), \delta=27.9(3 \times \mathrm{Me}), 34.6(\mathrm{NMe})$, $38.7\left(\mathrm{CH}_{2}\right), 51.9(\mathrm{CH}), 59.4(\mathrm{OMe}), 81.0(\mathrm{C}), 170.0(\mathrm{C}=0)$, $174.0 \mathrm{ppm} \quad(\mathrm{C}=0) . \quad[\mathrm{a}]_{\mathrm{D}}{ }^{20}=-0.5 \quad\left(c=1.21, \quad \mathrm{CHCl}_{3}\right) . \quad \mathrm{C}_{10} \mathrm{H}_{19} \mathrm{NO}_{4}$ [217], ESI-MS: $m / z$ (rel. int., \%) $=457$ (6) $[2 \mathrm{M}+\mathrm{Na}]^{+}, 435$ (4) $[2 \mathrm{M}+\mathrm{H}]^{+}, 240(30)[\mathrm{M}+\mathrm{Na}]^{+}, 218(100)[\mathrm{M}+\mathrm{H}]^{+}, 162(36)$.

Compound 4: Rhodamin $101(0.22 \mathrm{~g}, 0.440 \mathrm{mmol})$ and HATU $(0.33 \mathrm{~g}, 0.880 \mathrm{mmol})$ in $\mathrm{CH}_{2} \mathrm{Cl}_{2}(2 \mathrm{~mL})$ containing $\mathrm{NEt}_{3}(200 \mu \mathrm{L})$ were added to a solution of $3(0.10 \mathrm{~g}, 0.465 \mathrm{mmol})$. The mixture was stirred overnight at room temperature. Then it was diluted with $\mathrm{CH}_{2} \mathrm{Cl}_{2}(30 \mathrm{~mL})$, washed with water, $0.1 \mathrm{~N} \mathrm{H}_{2} \mathrm{SO}_{4}$, water, $\mathrm{NaHCO}_{3}$, water, brine (10 mL each time), and dried. After evaporation of the solvent the residue was purified on silica gel (100 g) with a $\mathrm{CH}_{2} \mathrm{Cl}_{2}-\mathrm{MeOH}$ mixture $(10: 1)$ to obtain a darkviolet solid, which was washed with ether and dried in vacuo; yield: $0.28 \mathrm{~g}(90 \%) .{ }^{1} \mathrm{H}$ NMR $\left(300 \mathrm{MHz}, \mathrm{CDCl}_{3}\right), \delta=1.38$ (s, $9 \mathrm{H}$ ), 1.87-2.02 (m, $4 \mathrm{H}, \mathrm{CH}_{2}$ in $\left.\mathrm{Rh}\right), 2.02-2.15\left(\mathrm{~m}, 4 \mathrm{H}, \mathrm{CH}_{2}\right.$ in $\left.\mathrm{Rh}\right)$, 2.31-2.42 (m, $1 \mathrm{H}, J=7.1, \mathrm{CH}), 2.58-2.72\left(\mathrm{~m}, 4 \mathrm{H}, \mathrm{CH}_{2}\right.$ in $\left.\mathrm{Rh}\right)$, 2.74-2.83 (m, $1 \mathrm{H}, J=7.1$ and $16.0, \mathrm{CH}), 2.91$ (s, 3H, NMe), 2.93-3.04 (m, 4 H, $\mathrm{CH}_{2}$ in Rh), 3.37 (s, 3H, OMe), 3.39-3.59 (m, $8 \mathrm{H}, \mathrm{CH}_{2}$ in $\left.\mathrm{Rh}\right), 4.65-4.73(\mathrm{~m}, 1 \mathrm{H}, J=7.1, \mathrm{CH}), 6.64-6.72(\mathrm{~m}$, $2 \mathrm{H}, \mathrm{CH}), 7.27-7.33(\mathrm{~m}, 1 \mathrm{H}, \mathrm{CH}), 7.45-7.53(\mathrm{~m}, 1 \mathrm{H}, \mathrm{CH}), 7.58-$ $7.69 \mathrm{ppm}(\mathrm{m}, 2 \mathrm{H}, \mathrm{CH}) . \mathrm{C}_{41} \mathrm{H}_{48} \mathrm{~N}_{3} \mathrm{O}_{6}(+) * \mathrm{OH}(-)[690(+) \star 17(-)]$, HR-MS (ESI, positive mode): $690.35357\left[\mathrm{M}^{+}\right]$(found), 690.35376 (calculated).

Compound 5: $1 \mathrm{~N} \mathrm{NaOH}(0.5 \mathrm{~mL})$ was added to a solution of compound $4(0.21 \mathrm{~g}, 0.3 \mathrm{mmol})$ in $\mathrm{MeOH}(1 \mathrm{~mL})$ and THF $(1 \mathrm{~mL})$, at $0{ }^{\circ} \mathrm{C}$. The mixture was stirred at room temperature for $3 \mathrm{~h}$. Then $1 \mathrm{~N} \mathrm{HCl}(0.7 \mathrm{~mL})$ was added to reach $\mathrm{pH} 2.2$ and extracted with $\mathrm{CH}_{2} \mathrm{Cl}_{2}(3 \times 5 \mathrm{~mL})$. The extract was washed with brine, dried over $\mathrm{MgSO}_{4}$, filtered, and evaporated. Yield: $0.2 \mathrm{~g}(90 \%)$ of a dark-violet solid. ${ }^{1} \mathrm{H} \mathrm{NMR}\left(300 \mathrm{MHz}, \mathrm{CDCl}_{3}\right), \delta=1.38(\mathrm{~s}, 9 \mathrm{H})$, 1.85-1.98 (m, $4 \mathrm{H}, \mathrm{CH}_{2}$ in $\left.\mathrm{Rh}\right), 1.98-2.10\left(\mathrm{~m}, 4 \mathrm{H}, \mathrm{CH}_{2}\right.$ in $\left.\mathrm{Rh}\right)$, 2.32-2.44 (m, $1 \mathrm{H}, J=7.1, \mathrm{CH}), 2.60-2.70\left(\mathrm{~m}, 4 \mathrm{H}, \mathrm{CH}_{2}\right.$ in $\left.\mathrm{Rh}\right)$, 2.72-2.84 (m, $1 \mathrm{H}, J=7.1$ and 16.0, $\mathrm{CH}), 2.92(\mathrm{~s}, 3 \mathrm{H}, \mathrm{NMe})$, 2.92-3.02 (m, 4 H, CH 2 in $\mathrm{Rh}), 3.30-3.56\left(\mathrm{~m}, 8 \mathrm{H}, \mathrm{CH}_{2}\right.$ in $\left.\mathrm{Rh}\right)$, 4.16 (br. s., $1 \mathrm{H}, \mathrm{NH}), 4.82-4.92(\mathrm{~m}, 1 \mathrm{H}, J=7.1, \mathrm{CH}), 6.58-6.76$ $(\mathrm{m}, 2 \mathrm{H}, \mathrm{CH}), 7.26-7.32(\mathrm{~m}, 1 \mathrm{H}, \mathrm{CH}), 7.48-7.62 \mathrm{ppm}(\mathrm{m}, 3 \mathrm{H}$, $\mathrm{CH}$ ). $\mathrm{C}_{41} \mathrm{H}_{45} \mathrm{~N}_{3} \mathrm{O}_{6}$ (zwitterion), HR-MS (ESI, positive mode): $676.33795[\mathrm{M}+\mathrm{H}]^{+}$(found), 676.33811 (calculated).

Compound 7: Compound 6 $6^{[20]}(150 \mathrm{mg}, 0.175 \mathrm{mmol}), \quad 5$ $(118 \mathrm{mg}, 0.175 \mathrm{mmol})$, and HATU $(133 \mathrm{mg}, 0.350 \mathrm{mmol})$ were mixed in $\mathrm{CH}_{2} \mathrm{Cl}_{2}(1 \mathrm{~mL})$ and $\mathrm{NEt}_{3}(100 \mu \mathrm{L})$ was added. The mixture was stirred at room temperature for $4 \mathrm{~h}$, then diluted with $\mathrm{CH}_{2} \mathrm{Cl}_{2}$ $(20 \mathrm{~mL})$, washed with water, $0.1 \mathrm{~N} \mathrm{H}_{2} \mathrm{SO}_{4}$, water, $\mathrm{NaHCO}_{3}$, water, brine, and dried. After evaporation of the solvent, the residue was purified on silica gel $(100 \mathrm{~g})$ with a $\mathrm{CH}_{2} \mathrm{Cl}_{2}-\mathrm{MeOH}$ mixture $(10: 1)$ as eluent. HPLC: $80 \rightarrow 100 \% \mathrm{~A}(20 \rightarrow 0 \% \mathrm{~B})$ for $0-20 \mathrm{~min}$, $100 \% \mathrm{~A}$ for $20-25 \mathrm{~min}, 1 \mathrm{~mL} \mathrm{~min}{ }^{-1}, 25^{\circ} \mathrm{C}, t_{\mathrm{R}}(\mathrm{OF})=21.0 \mathrm{~min}, t_{\mathrm{R}}$ $(C F)=22.1 \mathrm{~min}$, detection at $370 \mathrm{~nm}$ (isosbestic point). Yield $190 \mathrm{mg}(74 \%) .{ }^{1} \mathrm{H}$ NMR $(300 \mathrm{MHz}$, open form, mixture of rotamers, $\left.\mathrm{CDCl}_{3}\right), \delta=1.28-1.33 / 1.33-1.39(\mathrm{~m}, 9 \mathrm{H}), 1.87-2.02(\mathrm{~m}$, $4 \mathrm{H}, \mathrm{CH}_{2}$ in $\left.\mathrm{Rh}\right), 2.02-2.15\left(\mathrm{~m}, 4 \mathrm{H}, \mathrm{CH}_{2}\right.$ in $\left.\mathrm{Rh}\right), 2.17-2.26(\mathrm{~m}$, $6 \mathrm{H}, \mathrm{Me}), 2.32-2.39(\mathrm{~m}, 6 \mathrm{H}, \mathrm{Me}), 2.60-2.73\left(\mathrm{~m}, 5 \mathrm{H}, \mathrm{CH}_{2}\right.$ in $\mathrm{Rh}$, $\mathrm{CH}$ ), 2.78/2.86 (s, 3 H, NMe), 2.91/2.92 (s, 4 H, NMe, CH), 2.94$3.06\left(\mathrm{~m}, 4 \mathrm{H}, \mathrm{CH}_{2}\right.$ in $\left.\mathrm{Rh}\right), 3.38-3.61\left(\mathrm{~m}, 10 \mathrm{H}, \mathrm{CH}_{2}\right.$ in $\left.\mathrm{Rh}, \mathrm{CH}_{2}-\mathrm{N}\right)$, 4.05-4.17 (m, 2H, 0- $\left.\mathrm{CH}_{2}\right), 5.79 / 5.51(\mathrm{~m}, 1 \mathrm{H}, \mathrm{CH}), 6.62 / 6.68(\mathrm{~s}$, $1 \mathrm{H}, \mathrm{CH}$ in Rh), $6.71 / 6.72(\mathrm{~s}, 1 \mathrm{H}, \mathrm{CH}$ in $\mathrm{Rh}), 6.83-6.90(\mathrm{~m}, 2 \mathrm{H}$, 
$J=1.8$ and $8.8, \mathrm{CH}), 6.98-7.02(\mathrm{~m}, 1 \mathrm{H}, J=5.8, \mathrm{CH}), 7.08-7.10$ $(\mathrm{m}, 1 \mathrm{H}, J=5.8, \mathrm{CH}), 7.10-7.15(\mathrm{~m}, 1 \mathrm{H}, J=1.2$ and $3.8, \mathrm{CH})$, 7.33-7.40 (m, $1 \mathrm{H}, \mathrm{CH}$ in $\mathrm{Rh}), 7.40-7.54(\mathrm{~m}, 6 \mathrm{H}, 5 \times \mathrm{CH}, \mathrm{CH}$ in $\mathrm{Rh}), 7.58-7.69$ (m, 2H, CH in Rh), 8.54-8.60 ppm (m, $2 \mathrm{H}, \mathrm{CH})$. $\mathrm{C}_{80} \mathrm{H}_{76} \mathrm{~F}_{6} \mathrm{~N}_{5} \mathrm{O}_{6} \mathrm{~S}_{4}(+) * \mathrm{OH}(-)$ [1444(+)*17(-)], HR-MS (ESI, positive mode): $1444.45808\left[\mathrm{M}^{+}\right.$] (found), 1444.45771 (calculated), $722.73275[\mathrm{M}+\mathrm{H}]^{2+}$ (found), 722.73250 (calculated).

Compound 8: $\mathrm{Et}_{3} \mathrm{SiH}(25 \mathrm{mg}, 0.217 \mathrm{mmol})$ and TFA $(87 \mathrm{~mL}$, $1.130 \mathrm{mmol}$ ) were added at $0^{\circ} \mathrm{C}$ to a solution of compound 7 (127 mg, $0.087 \mathrm{mmol})$ in $\mathrm{CH}_{2} \mathrm{Cl}_{2}(0.2 \mathrm{~mL})$, under argon atmosphere. The mixture was kept overnight at $4^{\circ} \mathrm{C}$. Then solvent and TFA were evaporated, and the residue was purified on silica gel C18 (50 g) with a MeCN-water (9:1) $+0.1 \%$ v/v TFA mixture as eluent. Yield: $105 \mathrm{mg}$ (87\%). HPLC: $80 \rightarrow 100 \%$ A $(20 \rightarrow 0 \%$ B) for $0-20 \mathrm{~min}, 100 \% \mathrm{~A}$ from $20-25 \mathrm{~min}, 1 \mathrm{~mL} \mathrm{~min}^{-1}, 25^{\circ} \mathrm{C}, t_{\mathrm{R}}$ $(\mathrm{OF})=14.1 \mathrm{~min}, t_{\mathrm{R}}(\mathrm{CF})=21.3 \mathrm{~min}$, detection at $370 \mathrm{~nm}$ (isobestic point). ${ }^{1} \mathrm{H} N M R(600 \mathrm{MHz}$, open form, mixture of rotamers, $\left.\mathrm{CDCl}_{3}\right), \delta=1.85-2.00\left(\mathrm{~m}, 4 \mathrm{H}, \mathrm{CH}_{2}\right.$ in $\left.\mathrm{Rh}\right), 2.00-2.12(\mathrm{~m}, 4 \mathrm{H}$, $\mathrm{CH}_{2}$ in $\left.\mathrm{Rh}\right), 2.15-2.26(\mathrm{~m}, 6 \mathrm{H}, \mathrm{Me}), 2.28-2.40(\mathrm{~m}, 6 \mathrm{H}, \mathrm{Me})$, 2.60-2.73 (m, $5 \mathrm{H}, \mathrm{CH}_{2}$ in $\left.\mathrm{Rh}, \mathrm{CH}\right), 2.74-2.80(\mathrm{~m}, 3 \mathrm{H}, \mathrm{NMe})$, 2.82-2.95 (s, 4H, NMe, $\mathrm{CH}), 2.98-3.08\left(\mathrm{~m}, 4 \mathrm{H}, \mathrm{CH}_{2}\right.$ in $\left.\mathrm{Rh}\right)$, 3.38-3.52 (m, 8 H, CH in Rh), 3.50-3.58 (m, $\left.2 \mathrm{H}, \mathrm{CH}_{2}-\mathrm{N}\right), 4.01-$ $4.10\left(\mathrm{~m}, 2 \mathrm{H}, 0-\mathrm{CH}_{2}\right), 5.44 / 5.70(\mathrm{~m}, 1 \mathrm{H}, \mathrm{CH}), 6.60-6.74(\mathrm{~m}, 2 \mathrm{H}$, $\mathrm{CH}$ in $\mathrm{Rh}), 6.76-6.84(\mathrm{~m}, 2 \mathrm{H}, \mathrm{CH}), 6.92-7.00(\mathrm{~m}, 1 \mathrm{H}, \mathrm{CH})$, 7.02-7.10 (m, $1 \mathrm{H}, \mathrm{CH}), 7.15-7.20(\mathrm{~m}, 1 \mathrm{H}, \mathrm{CH}), 7.30-7.38(\mathrm{~m}$, $2 \mathrm{H}, \mathrm{CH}$ in Rh, $\mathrm{CH}), 7.40-7.48(\mathrm{~m}, 2 \mathrm{H}, \mathrm{CH}), 7.56-7.64(\mathrm{~m}, 2 \mathrm{H}$, $\mathrm{CH}), 7.68-7.74(\mathrm{~m}, 1 \mathrm{H}, \mathrm{CH}$ in $\mathrm{Rh}), 7.80-7.86(\mathrm{~m}, 2 \mathrm{H}, \mathrm{CH}$ in $\mathrm{Rh})$, 8.60-8.70 ppm (m, 2 H, CH). $\mathrm{C}_{76} \mathrm{H}_{67} \mathrm{~F}_{6} \mathrm{~N}_{5} \mathrm{O}_{6} \mathrm{~S}_{4}$ (zwitterion), HR-MS (ESI, positive mode): $1388.39508\left[M+\mathrm{H}^{+}\right.$(found), 1388.39566 (calculated).

Compound 10: $\left(c f^{[31]}\right) N, N, N^{\prime}, N^{\prime}$-Tetramethyl(succinimido)uronium tetrafluoroborate 9 (Alfa Aesar, $1.3 \mathrm{mg}, 4.4 \mu \mathrm{mol}$ ) and $\mathrm{N}, \mathrm{N}$ diisoprorilethylamine $(1 \mu \mathrm{L}, 5.4 \mu \mathrm{mol})$ were added to a solution of $25(5.0 \mathrm{mg}, 3.6 \mu \mathrm{mol})$ in dry DMF $(0.2 \mathrm{~mL})$. The mixture was stirred in the dark at room temperature for $2 \mathrm{~h}$ under argon, and the solvent was evaporated. Yield: $5 \mathrm{mg}$ (92\%). ${ }^{1} \mathrm{H}$ NMR (600 MHz, open form, mixture of rotamers, $\mathrm{CDCl}_{3}$ ), $\delta=1.93-2.03$ (m, $4 \mathrm{H}, \mathrm{CH}_{2}$ in $\mathrm{Rh}$ ), $2.04-2.15\left(\mathrm{~m}, 4 \mathrm{H}, \mathrm{CH}_{2}\right.$ in $\mathrm{Rh}$ ), $2.16-2.26$ $(\mathrm{m}, 6 \mathrm{H}, \mathrm{Me}), 2.28-2.41(\mathrm{~m}, 6 \mathrm{H}, \mathrm{Me}), 2.76\left(\mathrm{~s}, 4 \mathrm{H}, \mathrm{CH}_{2}\right.$ in $\left.\mathrm{NHS}\right)$, 2.60-3.15 (m, $16 \mathrm{H}, \mathrm{CH}_{2}$ in Rh, NMe, $\left.\mathrm{CH}\right), 3.42-3.65(\mathrm{~m}, 8 \mathrm{H}$, $\mathrm{CH}_{2}$ in $\left.\mathrm{Rh}\right), 3.50-3.70\left(\mathrm{~m}, 2 \mathrm{H}, \mathrm{CH}_{2}-\mathrm{N}\right), 4.00-4.20(\mathrm{~m}, 2 \mathrm{H}, \mathrm{O}-$ $\left.\mathrm{CH}_{2}\right)$, 5.64/5.94 (m, $\left.1 \mathrm{H}, \mathrm{CH}\right), 6.58-6.76(\mathrm{~m}, 2 \mathrm{H}, \mathrm{CH}$ in $\mathrm{Rh})$, 6.80-6.93 (m, 2H, CH), 6.97-7.03 (m, $1 \mathrm{H}, \mathrm{CH}), 7.06-7.17(\mathrm{~m}$, $2 \mathrm{H}, \mathrm{CH}), 7.37-7.54(\mathrm{~m}, 6 \mathrm{H}, \mathrm{CH}$ in $\mathrm{Rh}, \mathrm{CH}), 7.54-7.74(\mathrm{~m}, 3 \mathrm{H}$, $\mathrm{CH}$ in $\mathrm{Rh}), 8.53-8.62 \mathrm{ppm}(\mathrm{m}, 2 \mathrm{H}, \mathrm{CH}) . \mathrm{C}_{80} \mathrm{H}_{71} \mathrm{~F}_{6} \mathrm{~N}_{6} \mathrm{O}_{8} \mathrm{~S}_{4}(+)^{\star} \mathrm{OH}(-)$ [1485(+)*17(-)], ESI-MS: $m / z$ (rel. int., \%) =1485.42 (35) $\left[\mathrm{M}^{+}\right]$, 743.20936 (100) $[M+H]^{2+}$ (found), 743.20938 (calculated).

Synthesis of fluorescent nanoparticles: Silica nanoparticles doped only with the photochromic fluorescent dye Rh-AA-DAE were prepared according to a modification ${ }^{[18]}$ of the Stöber method. ${ }^{[32]}$ First, the amino reactive fluorescent probe (NHS ester) was coupled to (3-aminopropyl)triethoxysilane (APS, Aldrich) by stirring a mixture of both (fivefold excess of the silane) in ethanol at room temperature. After $8 \mathrm{~h}$, the mixture was diluted with ethanol, and measured volumes of tetraethyl orthosilicate (TEOS, Fluka) and ammonium hydroxide ( $28 \mathrm{w} \%$ in water, Aldrich) were added. The final size of the particles was determined by the concentration of TEOS and ammonia in the reaction vessel, according to previously described conditions. ${ }^{[19]}$ The samples were then stirred overnight at room temperature. The reaction was stopped by diluting the mixture with at least two volumes of solvent, and purified by at least three centrifugation-resuspension cycles. The molar ratio TEOS:Rh-AA-DAE was set to 600 to avoid particle agglomeration, which was observed for ratios smaller than 500 .

Dual-doped silica nanoparticles containing Rh-AA-DAE and Atto-647N (Atto-Tec, Germany), were prepared in a four-step procedure as follows. First, nonfluorescent silica cores of 52-nm diameter were prepared according to a water-in-oil microemulsion technique. ${ }^{[33]}$ Then, three shells were grown onto the cores based in a seeded growth technique early described by Philipse and $\mathrm{Vrij},{ }^{\left[{ }^{[4]}\right]}$ and afterwards adapted to include fluorescent markers. ${ }^{[18]}$ The volume of TEOS to be added in each step $\left(V_{1}\right)$ was calculated to obtain the desired increase of size from $\phi_{0}$ to $\phi_{1}$ (diameter of the seeded particles and the final one, respectively) according to the following equation: ${ }^{[35]}$

$V_{1}=V_{0}\left[\left(\phi_{1} / \phi_{0}\right)-1\right]$

where $V_{0}$ is the volume of TEOS used to prepare the total amount of seeded particles. Then, the resulting mixture $(100 \mu \mathrm{L})$ after coupling Atto647N-NHS and APS $(0.5 \mathrm{mg}$ and $0.8 \mu \mathrm{L}$, respectively) was added to $5 \mathrm{~mL}$ of a suspension of the cores containing $3 \mathrm{mg} \mathrm{SiO}_{2} \mathrm{~mL}^{-1}\left(11 \mu \mathrm{L} \mathrm{TES} \mathrm{mL}{ }^{-1}\right)$. TEOS $(50 \mu \mathrm{L})$ and ammonium hydroxide $(300 \mu \mathrm{L})$ were added, and the mixture was stirred in the dark for $16 \mathrm{~h}$. The particles (66-nm diameter) were purified by two centrifugation-resuspension cycles to remove possible amounts of the unreacted fluorescent dye, and then resuspended in $5 \mathrm{~mL}$ of ethanol. A second portion of TEOS $(250 \mu \mathrm{L})$ was added, together with ammonium hydroxide $(300 \mu \mathrm{L})$, and the mixture was allowed to react for another $16 \mathrm{~h}$. A small aliquot was extracted to measure the particle size at this point (106-nm diameter). Finally, a third portion of TEOS $(300 \mu \mathrm{L})$, deionized water $(200 \mu \mathrm{L})$, and the reaction mixture $(100 \mu \mathrm{L})$ after coupling Rh-AA-DAE $(3 \mathrm{mg})$ and APS $(2.5 \mu \mathrm{L})$ were added. The reaction was stirred for $16 \mathrm{~h}$ and the resulting dualdoped nanoparticles were purified by three centrifugation-resuspension cycles, and resuspended in $3 \mathrm{~mL}$ of ethanol.

Particles with a photochromic fluorescent shell, doped with Rh-AA-DAE, and a nonfluorescent core were prepared following a seeded growth procedure similar to the one already described. All particle sizes were determined by transmission electron microscopy.

Confocal fluorescence microscopy measurements: Singleand double-labeled NPs were observed in a confocal microscope featuring an immersion objective lens of 1.3 numerical aperture (ACS, 60x, Leica Microsystems, Wetzlar, Germany). A diode laser at $375 \mathrm{~nm}$ (iPulse-375, Toptica Photonics AG, Gräfelfing, Germany) and a diode-pumped solid-state laser at $671 \mathrm{~nm}$ (DPSSL Monolas-671-300MM, Alphalas, Göttingen, Germany) were used to drive the on and off photochromic reaction, respectively, and a green HeNe laser at $543 \mathrm{~nm}$ (25LGP193-230, Melles Griot, Carlsbad, CA, USA) was used to excite the fluorescent moiety. All lasers were collinearly aligned by means of dichroic mirrors, and the temporal sequence of their pulses was controlled with a programmable pulse generator (9500 Series, Quantum Composers, Bozeman, MT, USA). The 375-nm diode laser was directly modulated and the HeNe laser and the DPSSL were modulated by 
means of two acousto-optic tunable filters (AOTF) (AA.AOTF.nCTN1003, AA Optoelectronic, St. Remy, France). The detectors were gated simultaneously with the excitation laser. Two avalanche photodiodes collected the signal arising from each fluorophore; the first from $\mathrm{Rh}(555-635 \mathrm{~nm})$ and the second from Atto647N $(680-720 \mathrm{~nm})$. The excitation of Atto647N $\left(\lambda_{\text {ex }}=\right.$ $642 \mathrm{~nm} ; \lambda_{\text {em }}=670 \mathrm{~nm}$, in silica) was performed with the red laser at $671 \mathrm{~nm}$ used to modulate Rh-AA-DAE. Since the quantum efficiency of the photoreaction that switches the fluorescence on is low, ${ }^{[20]}$ the signal readout of Atto647N could be performed with almost no perturbation to the PC system. Thus, the particles were simultaneously imaged with the two detection channels.

For resolution enhancement measurements (RESOLFT microscopy), a phase shift of $\pi$ radians $^{[36]}$ was applied to the laser used to drive the photochromic reaction to the off state, in a half-plane of the entrance pupil such that it features a nodal $y-z$ plane. Thus, the resolution enhancement was obtained only in the $x$ axis. The $\pi$ phase was produced with a spatial light modulator (X8267-3558, Hamamatsu Photonics K. K., Hamamatsu City, Japan) whose screen was projected into the entrance pupil of the objective lens. Further details on the setup are described elsewhere. ${ }^{[27]}$

The samples were prepared by spreading $20 \mu \mathrm{L}$ of a diluted suspension of the beads onto clean microscope coverslips and then allowed to dry in air. A drop of the immersion fluid (oil, glycerol or water) was added, the sample was sandwiched between the coverslip and a regular microscope slide, and then glued together with an epoxy resin.

\section{Acknowledgement}

This work was supported by BMBF (NanoBiophotonics program) and the European Commission through the SPOTLITE project and a Marie Curie Fellowship to M.L.B. The authors thank D. Riedel for TEM measurements and J. Jethwa for a critical reading of the manuscript.

[1] Molecular Switches (Ed.: B. L. Feringa), Wiley-VCH, Weinheim, Germany, 2001.

[2] M. Irie, Chem. Rev. 2000, 100, 1685-1716.

[3] J. C. Politz, Trends Cell Biol. 1999, 9, 284-287.

[4] X. J. Zhao, R. Tapec-Dytioco, W. H. Tan, J. Am. Chem. Soc. 2003, 125, 11474-11475.

[5] S. Santra, P. Zhang, K. M. Wang, R. Tapec, W. H. Tan, Anal. Chem. 2001, 73, 4988-4993.

[6] S. T. Selvan, T. T. Tan, J.Y. Ying, Adv. Mater. 2005, 17, 16201625.

[7] L. Wang, C. Y. Yang, W. H. Tan, Nano Lett. 2005, 5, 37-43.
[8] L. Wang, W. H. Tan, Nano Lett. 2006, 6, 84-88.

[9] S. Brandriss, S. Margel, Langmuir 1993, 9, 1232-1240.

[10] B. K. An, S. K. Kwon, S. D. Jung, S. Y. Park, J. Am. Chem. Soc. 2002, 124, 14410-14415.

[11] I. L. Medintz, S. A. Trammell, H. Mattoussi, J. M. Mauro, J. Am. Chem. Soc. 2004, 126, 30-31.

[12] S. J. Lim, B. K. An, S. D. Jung, M. A. Chung, S.Y. Park, Angew. Chem. 2004, 116, 6506-6510; Angew. Chem. Int. Ed. 2004, 43, 6346-6350.

[13] E. Jares-Erijman, L. Giordano, C. Spagnuolo, K. Lidke, T. M. Jovin, Mol. Cryst. Liq. Cryst. 2005, 430, 257-265.

[14] M. Q. Zhu, L. Y. Zhu, J. J. Han, W. W. Wu, J. K. Hurst, A. D. Q. Li, J. Am. Chem. Soc. 2006, 128, 4303-4309.

[15] L. Zhu, W. Wu, M. Q. Zhu, J. J. Han, J. K. Hurst, A. D. Li, J. Am. Chem. Soc. 2007, 129, 3524-3526.

[16] X. Michalet, F. F. Pinaud, L. A. Bentolila, J. M. Tsay, S. Doose, J. J. Li, G. Sundaresan, A. M. Wu, S. S. Gambhir, S. Weiss, Science 2005, 307, 538-544.

[17] T. K. Jain, I. Roy, T. K. De, A. Maitra, J. Am. Chem. Soc. 1998, 120, 11 092-11095.

[18] A. van Blaaderen, A. Vrij, Langmuir 1992, 8, 2921-2931.

[19] G. H. Bogush, M. A. Tracy, C. F. Zukoski, J. Non-Cryst. Solids 1988, 104, 95-106.

[20] M. Bossi, V. Belov, S. Polyakova, S.W. Hell, Angew. Chem. 2006, 118, 7623-7627; Angew. Chem. Int. Ed. 2006, 45, $7462-7465$

[21] K. H. Knauer, R. Gleiter, Angew. Chem. 1977, 89, 116-117; Angew. Chem. Int. Ed. Engl. 1977, 16, 113-113.

[22] D. H. Kwon, H. W. Shin, E. Kim, D. W. Boo, Y. R. Kim, Chem. Phys. Lett. 2000, 328, 234-243.

[23] S. W. Hell, Nat. Biotechnol. 2003, 21, 1347-1355.

[24] S. W. Hell, K. I. Willig, M. Dyba, S. Jakobs, L. Kastrup, V. Westphal in Handbook of Biological Confocal Microscopy (Ed.: J. Pawley), Springer, New York, 2006, pp. 571-579.

[25] T. A. Klar, S. Jakobs, M. Dyba, A. Egner, S. W. Hell, Proc. Natl. Acad. Sci. USA 2000, 97, 8206-8210.

[26] M. Hofmann, C. Eggeling, S. Jakobs, S. W. Hell, Proc. Natl. Acad. Sci. USA 2005, 102, 17 565-17569.

[27] M. Bossi, J. Fölling, M. Dyba, V. Westphal, S. W. Hell, New J. Phys. 2006, 8, 275.

[28] V. Westphal, S. W. Hell, Phys. Rev. Lett. 2005, 94, 143903.

[29] S. W. Hell, Science 2007, 316, 1153-1158.

[30] H. OW, D. R. Larson, M. Srivastava, B. A. Baird, W. W. Webb, U. Wiesner, Nano Lett. 2005, 5, 113-117.

[31] D. Ossipov, S. Gohil, J. Chattopadhyaya, J. Am. Chem. Soc. 2002, 124, 13416-13433.

[32] W. Stöber, A. Fink, E. Bohn, J. Colloid Interface Sci. 1968, 26, 62-69.

[33] F. J. Arriagada, K. Osseo-Asare, J. Colloid Interface Sci. 1999, 211, 210-220.

[34] A. P. Philipse, A. Vrij, J. Chem. Phys. 1987, 87, 5634-5643.

[35] A. van Blaaderen, J. van Geest, A. Vrij, J. Colloid Interface Sci. 1992, 154, 481-501.

[36] S.W. Hell in Topics in Fluorescence Spectroscopy, Vol. 5 (Ed.: J. R. Lakowicz), Plenum, New York, 1997, pp. 361-422.

Received: June 22, 2007

Published online on December 6, 2007 